\section{Silver Iodate}

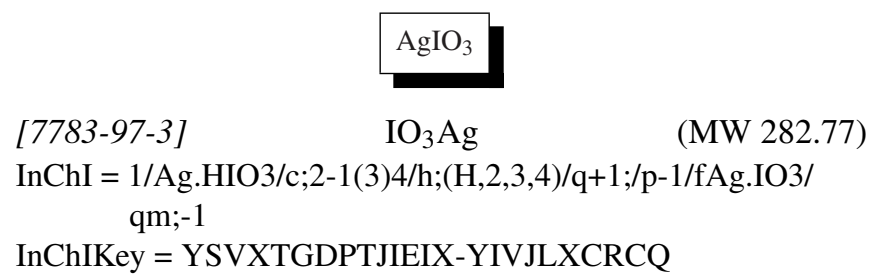

(reagent used as a versatile oxidative amidation and cyclization component)

Physical Data: $\mathrm{mp}>200^{\circ} \mathrm{C} ; d 5.53 \mathrm{~g} \mathrm{~cm}^{-3}$.

Solubility: soluble in aqueous ammonia; practically insoluble in water $\left(0.3 \mathrm{~g} \mathrm{~L}^{-1}\right.$ at $\left.10^{\circ} \mathrm{C}\right)$.

Form Supplied in: white crystalline powder; commercially available.

Handling, Storage, and Precautions: irritant; light sensitive; causes ignition with reducing agents or combustibles; store in cool and dry conditions in well-sealed containers; handle in fume hood.

Oxidative Cyclizations. Like copper(II) acetate ${ }^{\mathbf{1}}$ and other metal salts, ${ }^{2}$ silver iodate has been utilized as an oxidant to transform $a, c$-biladienes ${ }^{\mathbf{3}, \mathbf{4}}$ into porphyrins via cyclization. ${ }^{\mathbf{5}}$ For example, treatment of an $a, c$-biladiene containing a free $\beta$-position adjacent to the terminal methyl group with zinc acetate and silver iodate delivers the corresponding porphyrin in $31 \%$ yield in dimethylformamide at high temperature $\left(160^{\circ} \mathrm{C}\right)$ after the removal of zinc (eq 1). It is necessary to use anhydrous zinc acetate as a chelating agent to bring the methyl groups in close proximity and promote the cyclization., $\mathbf{1 , 6}$ In the absence of chelating agents or in the presence of other agents such as magnesium or mercuric salts, the cyclization gives low yields under the same conditions. In the presence of copper(II) chloride, silver iodate can also promote the cyclization at room temperature rather than the typical harsh conditions involving boiling dimethylformamide (eq 2). ${ }^{3,5}$ It has been shown that the formation of a stable square planar chelate between copper and the $a, c$-biladiene results in the straightforward oxidation to the planar porphyrin. ${ }^{1}$

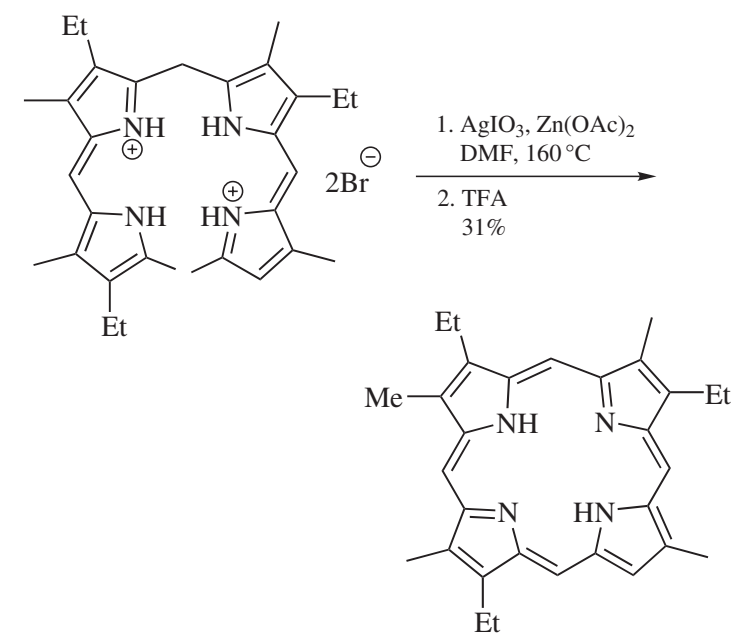

a,c-Biladienes with exocyclic rings have been utilized in silver iodate-zinc acetate mediated cyclization. ${ }^{\mathbf{7 , 8}}$ The reaction of a,c-biladienes bearing six-membered carbocyclic rings with silver iodate in dimethylformamide followed by demetalation with $5 \%$ sulfuric acid in trifluoroacetic acid affords the isolated porphyrin in $12 \%$ yield (eq 3 ). The syntheses of petroporphyrin bearing a sevenmembered exocyclic ring, such as $\mathrm{C}_{32}$ 15,17-butanoporphyrin ${ }^{9}$ and its 3-methyl homolog, ${ }^{\mathbf{1 0}}$ have been reported by Lash and Johnson (eq 4). ${ }^{\mathbf{8}}$ Treatment of $a, c$-biladiene salts with silver iodate and zinc acetate affords desired petroporphyrins via oxidative cyclization in good yields under mild conditions. ${ }^{\mathbf{5}}$ However, attempts to cyclize $a, c$-biladienes bearing exocyclic rings under other conditions such as copper(II) chloride in dimethylformamide or copper(II) acetate in pyridine result in only trace amounts of the cyclized petroporphyrins due to the geometry enforced on the tetrapyrrolic intermediate by the carbocyclic ring conformation. ${ }^{\mathbf{1 1}}$ It has been shown that the silver iodate-zinc acetate mediated conditions can increase the stability of the cyclizing tetrapyrroles, resulting in improvement of the cyclization yield. ${ }^{\mathbf{1 2}}$

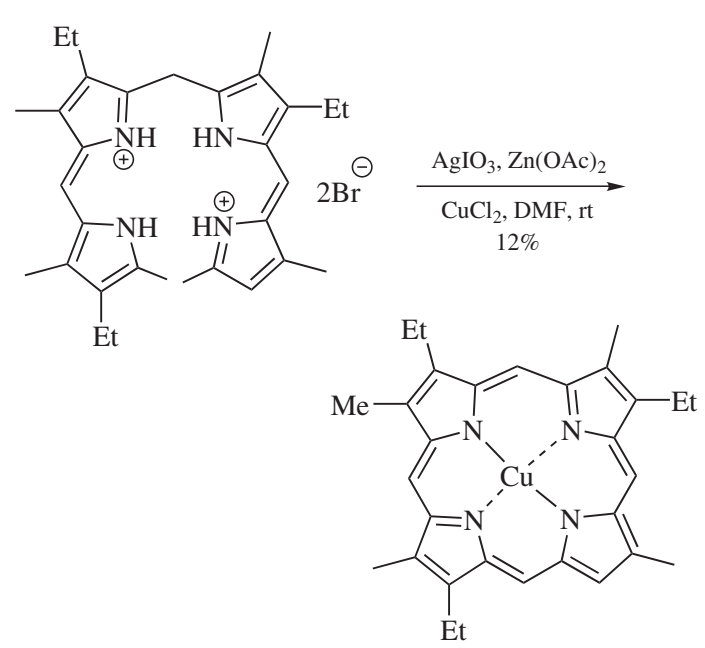

Silver iodate has been applied toward the multistep synthesis of meso- and $\beta$-substituted chlorin building blocks. ${ }^{13,14}$ Chlorins provide the basis for plant photosynthesis, ${ }^{15,16}$ but the unavailability of suitable chlorin building blocks has led to the inevitable use of synthetic model systems that employ surrogate porphyrins. ${ }^{17,18} \mathrm{~A}$ bromodipyrromethane carbinol is prepared by acylation and bromination of a 5-substituted dipyrromethane followed by reduction. Chlorin formation is achieved by acid-catalyzed condensation and metal-mediated oxidative cyclization. The applied copper-free conditions use zinc acetate, silver iodate, and piperidine in toluene at $80^{\circ} \mathrm{C}$ for $2 \mathrm{~h}$ to obtain the zinc chlorins in around $10 \%$ yield (eq 5). These can be easily demetalated to give the corresponding base chlorins. This general synthetic process is applicable to a range of meso- and $\beta$-substituents (eq 6). The metal-mediated oxidative cyclization of a dihydrobilene results in the final formation of the chlorins. This process proceeds in five steps: oxidation of the dihydrobilene intermediate to afford a dihydrobilatriene, imine-enamine tautomerization, metal complexation with a divalent metal ion, carbon-carbon bond formation through an $18 \pi$-electrocyclization, ${ }^{19}$ and hydrogen bromide $(\mathrm{HBr})$ elimination to yield the 
final chlorin. ${ }^{13,20,21}$ Although very little is known of the reactivity of the intermediates or the efficacy of the individual reactions, factors that can affect the outcome of this process include choice of solvent, metal complex, oxidant, temperature, and base. As described above, silver iodate is more commonly used in the cyclization of $a, c$-biladienes and it is believed that silver cations facilitate the elimination of bromides during chlorin formation. In studies of the cyclization reaction, it has been found that various quinines and oxidants in place of silver iodate do not produce the desired product. Similarly, combinations of the oxidants manganese dioxide and silver iodate in toluene or 1,4-dioxane show no improvement in the yield of the chlorin product. ${ }^{\mathbf{1 3}, 14}$
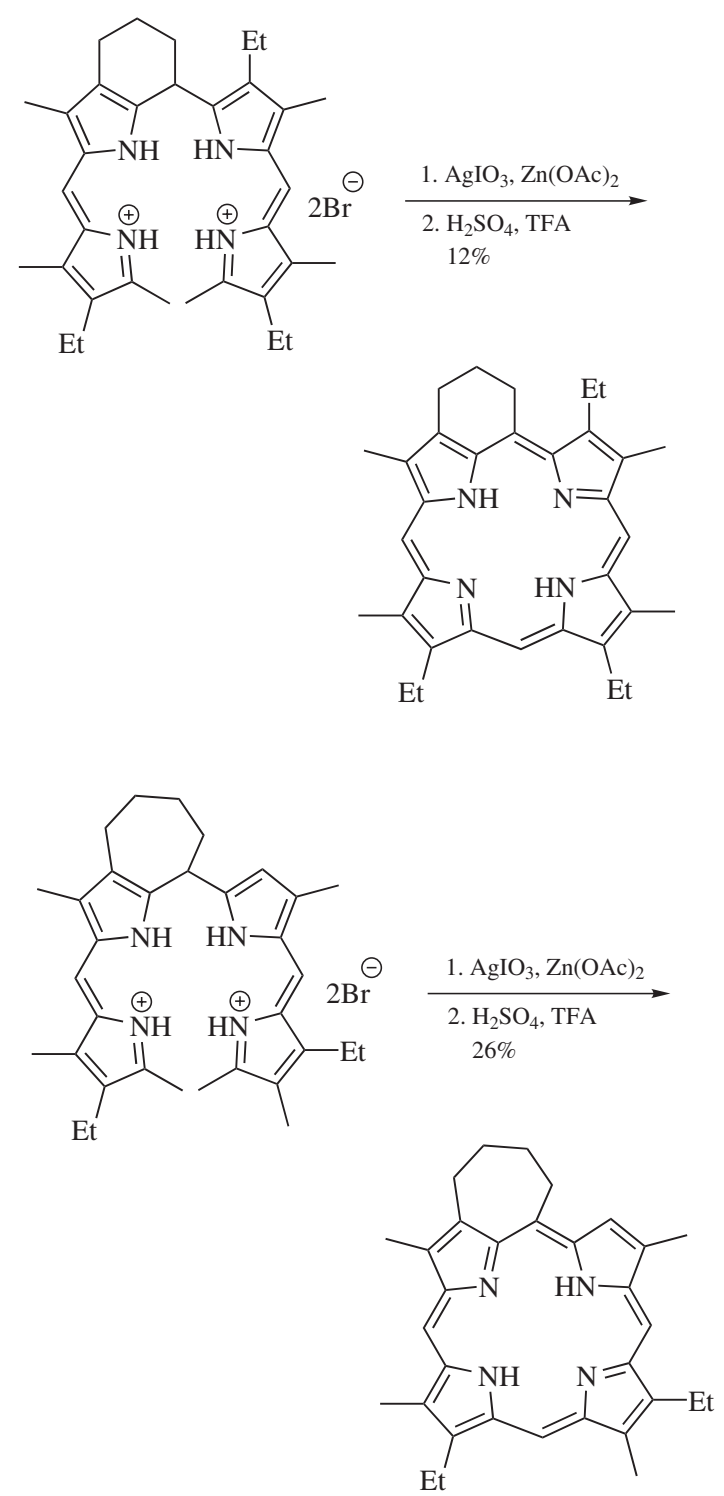

The synthesis of Type E dinaphthoporphyrin systems has been achieved using cyclization of $a, c$-biladiene intermediates with silver iodate and zinc acetate. ${ }^{\mathbf{2 2}}$ While the conventional cyclization procedure using copper(II) chloride in dimethylformamide produces virtually none of the desired porphyrin products, treatment with silver iodate and zinc acetate in dimethylformamide results in the zinc complex. ${ }^{\mathbf{5 , 8}}$ Demetalation with trifluoroacetic acid pro- vides the dinaphthoporphyrin in $6.8 \%$ yield (eq 7$)$. This low yield is thought to be due to deleterious steric interactions between the two naphthalene units. In addition, the purity of the $a, c$-biladiene may also be an important factor. ${ }^{22}$

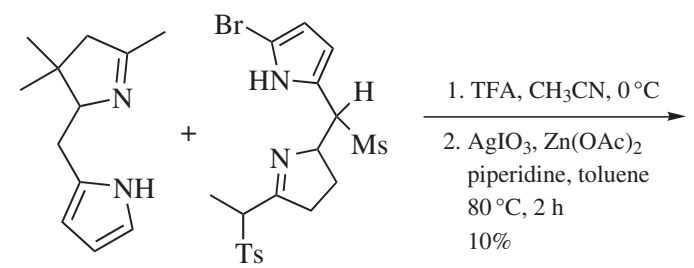

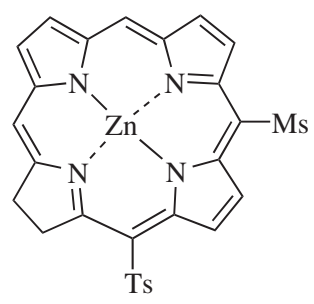

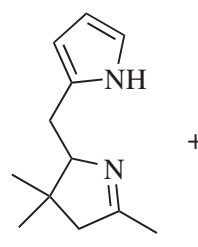<smiles>Cc1ccc(C(O)c2ccc(Cc3[nH]c(Br)cc3-c3ccc(I)cc3)[nH]2)cc1</smiles>
$\underset{\begin{array}{l}\text { 2. } \mathrm{TFA}, \mathrm{CH}_{3} \mathrm{CN} \\ \text { piperidine, toluene }\end{array}}{\stackrel{\mathrm{Zn}(\mathrm{OAc})_{2}}{\longrightarrow}}$ $80^{\circ} \mathrm{C}, 2.5 \mathrm{~h}$ $18 \%$

Oxidative Amidations. The use of silver iodate has been reported in the copper-catalyzed oxidative amidation reactions of simple aldehydes and amines. ${ }^{23}$ After screening a variety of copper salts, copper(I) iodide has been determined to be the most effective catalyst to generate the desired amide. Reducing catalyst loading results in a significant increase in amide formation. For example, the amidation of benzaldehyde with ethylamine hydrochloride gives a quantitative yield under silver iodate mediated conditions (eq 8). A proposed mechanism of the oxidative amidation with silver iodate and copper(I) iodide includes several steps such as deprotonation of amine hydrochloride salts to obtain free amines, nucleophilic addition to generate carbinolamine intermediates, and final oxidation to deliver desired amide products. ${ }^{24,25}$ 
The addition of a base improves the amidation reaction significantly. Although the base has been shown to be critical for the success of the amidation reaction, it is also the source of undesirable side reactions. An insoluble base such as $\mathrm{CaCO}_{3}$ allows clean and successful reactions.

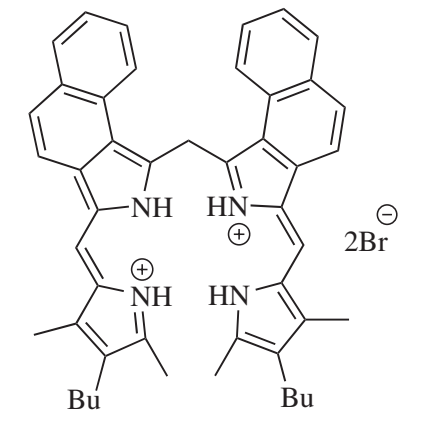

$$
\begin{aligned}
& \begin{array}{l}
\text { 1. } \mathrm{AgIO}_{3}, \mathrm{Zn}(\mathrm{OAc})_{2} \\
\mathrm{DMF}, 160^{\circ} \mathrm{C}
\end{array} \\
& \stackrel{\text { 2. TFA }}{6.8 \%}
\end{aligned}
$$

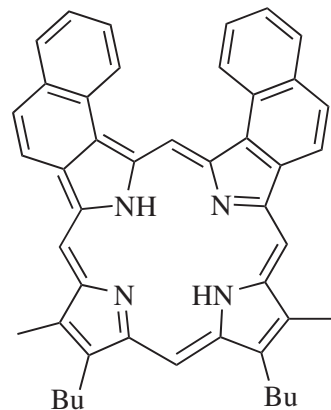

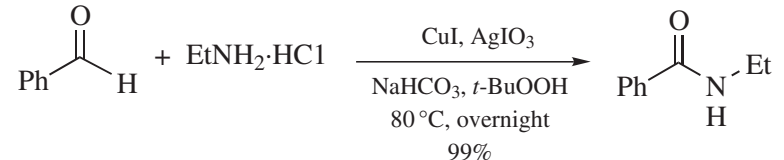

The scope of the oxidative amidation reaction includes a variety of aldehydes and amine hydrochloride salts. The optimized reaction conditions entail the use of 1.0 equiv of aldehyde, 1.5 equiv of amine hydrochloride salt, 1.1 equiv of calcium carbonate, 1.1 equiv of tert-butyl hydroperoxide, ${ }^{\mathbf{2 6}} 1.0 \mathrm{~mol} \%$ of copper(I) iodide, and $1.0 \mathrm{~mol} \%$ of silver iodate in acetonitrile. ${ }^{23}$ Amidation occurs even in the presence of other electrophiles such as alkyl chlorides and esters. The reaction of benzaldehyde with cyclohexylamine hydrochloride salt affords the corresponding amide in $73 \%$ yield (eq 9), but the same reaction using tert-butylamine hydrochloride leads to a lower yield of $39 \%$ due to steric effects of the bulky tert-butyl group. The oxidative amidation is also compatible with a variety of electron-rich and electron-poor aryl aldehydes. Treatment of ethyl glycinate hydrochloride with 4methoxybenzaldehyde produces the desired amide in $78 \%$ yield (eq 10); however, the reaction with 4-nitrobenzaldehyde gives the corresponding amide in $49 \%$ yield. It has also been shown that the oxidative amidation reaction of optically active amino esters under silver iodate and copper(I) iodide catalyzed conditions generates amides in high yields without racemization (eq 11). ${ }^{\mathbf{2 3}}$

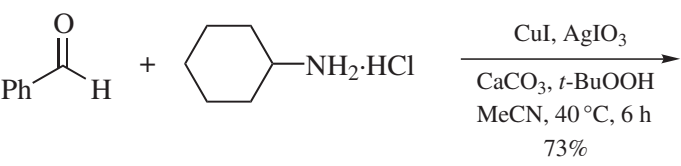<smiles>O=C(NC1CCCCC1)c1ccccc1</smiles><smiles>CCOC(=O)CN</smiles><smiles>CCOC(=O)CNC(=O)c1ccc(OC)cc1</smiles>
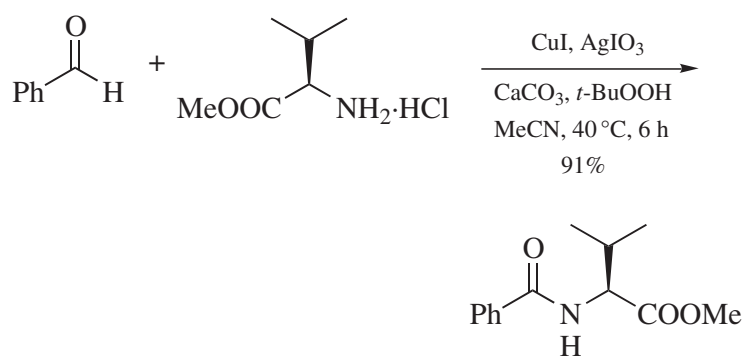

1. Johnson, A. W.; Kay, I. T., J. Chem. Soc. 1961, 2418.

2. (a) Grigg, R.; Johnson, A. W.; Kenyon, R.; Math, V. B.; Richardson, K., J. Chem. Soc. 1969, 176. (b) Clarke, D. A.; Grigg, R.; Harris, R. L. N.; Johnson, A. W.; Kay, I. T.; Shelton, K. W., J. Chem. Soc. 1967, 1648. (c) Dolphin, D.; Harris, R. L. N.; Huppatz, J.; Johnson, A. W.; Kay, I. T., J. Chem. Soc. 1966, 30

3. Smith, K. M.; Kehres, L. A., J. Chem. Soc., Perkin Trans. 1 1983, 2329.

4. Smith, K. M.; Langry, K. C.; Minnetian, O. M., J. Org. Chem. 1985, 49, 4602.

5. Smith, K. M.; Minnetian, O. M., J. Chem. Soc., Perkin Trans. 1 1986, 277.

6. Cavaleiro, J. J. A.; Rocha Gonsalves AMd'A, Kenner, G. W.; Smith, K. M., J. Chem. Soc., Perkin Trans. 1 1974, 1771.

7. Lash, T. D., Tetrahedron Lett. 1988, 29, 6877.

8. Lash, T. D.; Johnson, M. C., Tetrahedron Lett. 1989, 30, 5697.

9. Wolff, G. A.; Murray, M.; Maxwell, J. R.; Hunter, B. K.; Sanders, J. K. M., J. Chem. Soc., Chem. Commun. 1983, 922.

10. Chicarelli, M. I.; Wolff, G. A.; Murray, M.; Maxwell, J. R., Tetrahedron 1984, 40, 4033.

11. Flaugh, M. E.; Rapoport, H., J. Am. Chem. Soc. 1968, 90, 6877.

12. Clezy, P. S.; Fookes, C. J. R.; Prashar, J. K., J. Chem. Soc., Chem. Commun. 1988, 83.

13. Strachan, J.-P.; O'Shea, D. F.; Balasubramanian, T.; Lindsey, J. S., J. Org. Chem. 1999, 65, 3160.

14. Balasubramanian, T.; Strachan, J. P.; Boyle, P. D.; Lindsey, J. S., J. Org. Chem. 2000, 65, 7919 .

15. Scheer, H., InChlorophylls, Scheer, H., Ed.; CRC Press: Boca Raton, 1991, p. 3. 
16. Chiu, J. T.; Loewen, P. C.; Switala, J.; Gennis, R. B.; Timkovich, R., J. Am. Chem. Soc. 1989, 111, 7046.

17. Lindsey, J. S.; In The Porphyrin Handbook; Kadish, K. M.; Smith, K. M.; Guilard, R., Eds.; Academic Press: San Diego, 2000, Vol. 1, 45.

18. Lindsey, J. S.; Prathapan, S.; Johnson, T. E.; Wagner, R. W., Tetrahedron 1994, 50, 8941 .

19. (a) Montforts, F.-P., Angew. Chem., Int. Ed. Engl. 1981, 20, 778. (b) Montforts, F.-P.; Schwartz, U. M., Angew. Chem., Int. Ed. Engl. 1985, 24, 775 .

20. Battersby, A. R.; Fookes, C. J. R.; Snow, R. J., J. Chem. Soc., Perkin Trans. 1 1984, 2725.

21. Battersby, A. R.; Fookes, C. J. R.; Snow, R. J., J. Chem. Soc., Perkin Trans. 1 1984, 2733.
22. Manley, J. M.; Roper, T. J.; Lash, T. D., J. Org. Chem. 2005, 70, 874.

23. Yoo, W. J.; Li, C. J., J. Am. Chem. Soc. 2006, 128, 13064.

24. Gopinath, R.; Patel, B. K., Org. Lett. 2000, 2, 577.

25. (a) Himo, F.; Eriksson, L. A.; Maseas, F.; Siegbahn, P. E. M., J. Am. Chem. Soc. 2000, 122, 8031. (b) Whittaker, M. M.; Ballou, D. P.; Whittaker, J. W., Biochemistry 1998, 37, 8426. (c) Wachter, R. M.; Montague-Smith, M. P.; Branchaud, B. P., J. Am. Chem. Soc. 1997, 119, 7743.

26. Larock, R. C. Comprehensive Organic Transformations; VCH: New York, 1999.

Shuh-Kuen Chang \& Young In Oh California Institute of Technology, Pasadena, CA, USA 